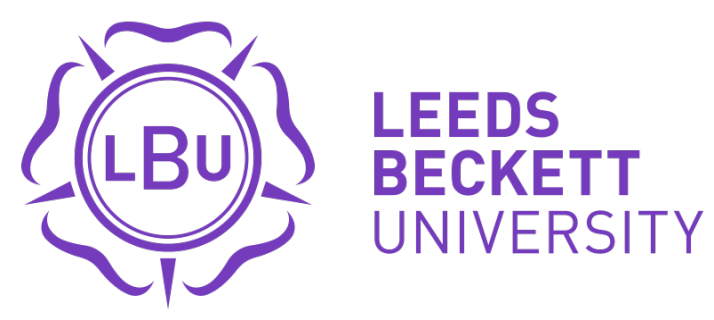

Citation:

Bissas, A and Paradisis, GP and Nicholson, G and Walker, J and Hanley, B and Havenetidis, $\mathrm{K}$ and Cooke, CB (2020) Development and Maintenance of Sprint Training Adaptations : An Uphill-Downhill Study. Journal of Strength and Conditioning Research. ISSN 1064-8011 DOI: https://doi.org/10.1519/JSC.0000000000003409

Link to Leeds Beckett Repository record:

https://eprints.leedsbeckett.ac.uk/id/eprint/6561/

Document Version:

Article (Accepted Version)

This is a post-peer-review, pre-copyedit version of an article published in Journal of Strength and Conditioning Research.

The aim of the Leeds Beckett Repository is to provide open access to our research, as required by funder policies and permitted by publishers and copyright law.

The Leeds Beckett repository holds a wide range of publications, each of which has been checked for copyright and the relevant embargo period has been applied by the Research Services team.

We operate on a standard take-down policy. If you are the author or publisher of an output and you would like it removed from the repository, please contact us and we will investigate on a case-by-case basis.

Each thesis in the repository has been cleared where necessary by the author for third party copyright. If you would like a thesis to be removed from the repository or believe there is an issue with copyright, please contact us on openaccess@leedsbeckett.ac.uk and we will investigate on a case-by-case basis. 


\title{
DEVELOPMENT AND MAINTENANCE OF SPRINT TRAINING
}

ADAPTATIONS: AN UPHILL-DOWNHILL STUDY

\author{
Athanassios Bissas ${ }^{1}$, Giorgos P. Paradisis ${ }^{2}$, Gareth Nicholson ${ }^{3}$, Josh Walker ${ }^{3}$, Brian \\ Hanley $^{3}$, Konstantinos Havenetidis ${ }^{4}$ and Carlton B. Cooke ${ }^{5}$
}

${ }^{1}$ Athletics Biomechanics, Leeds, United Kingdom
${ }^{2}$ Athletics Sector, School of Physical Education \& Sport Science, National \& Kapodistrian
University of Athens, Athens, Greece
${ }^{3}$ Carnegie School of Sport, Leeds Beckett University, Leeds, United Kingdom
${ }^{4}$ Faculty of Physical \& Cultural Education, Hellenic Army Academy, Attica, Greece
${ }^{5}$ School of Social and Health Sciences, Leeds Trinity University, Leeds, United Kingdom

Date of submission: 14-07-2019

Corresponding author: Giorgos P Paradisis

Athletics Sector, Faculty of Physical Education \& Sport Science, National \&

Kapodistrian University of Athens, Ethn. Antistasis 41, Dafni, Athens, 172 37, Greece

Tel: + 302107276167

E-mail: gparadi@phed.uoa.gr

Running title: Uphill-downhill training and detraining

No funding was received for this work from NIH, Wellcome Trust, Howard Hughes

Medical Institute, or any others. All authors report no conflict of interest. 
DEVELOPMENT AND MAINTENANCE OF SPRINT TRAINING ADAPTATIONS:

AN UPHILL-DOWNHILL STUDY 


\section{ABSTRACT}

We examined the development of performance adaptations resulting from an uphill-downhill training program and monitored the decline of adaptations during detraining. Twenty-eight males were randomly assigned to one of two sprint training groups who trained three times per week for six weeks, and a control group (C). The Uphill-downhill group (U+D) trained on an $80-\mathrm{m}$ platform with $3^{\circ}$ slopes whereas the Horizontal $(\mathrm{H})$ group trained on flat track. Participants were tested for maximal running speed (MRS), associated kinematics and leg strength pre- and post-training, with U+D participants also tested after weeks 2 and 4 of training, and after a 3-week detraining period. The U+D group increased their MRS by $3.7 \%$ (from $8.75 \pm 0.72$ to $9.07 \pm 0.64 \mathrm{~m} \cdot \mathrm{s}^{-1}, P<0.05$ ), their stride rate by $3.1 \%$ (from $4.21 \pm 0.21$ to $4.34 \pm 0.18 \mathrm{~Hz}, P<0.05$ ) and their knee extensors' maximum isometric force by $21 \%$ (from $2242 \pm 489$ to $2712 \pm 498 \mathrm{~N}, P<0.05)$ after training. The time course of changes showed declines for weeks 1-4 (1.4-5.1\%) but an ascending trend of improvement compensated all losses by the end of week $6(P<0.05)$. During detraining, no decreases occurred. No changes were observed for the $\mathrm{H}$ and $\mathrm{C}$ groups. The minimum period to produce positive effects was six weeks, with a very good standard of performance maintained three weeks post-training. $\mathrm{U}+\mathrm{D}$ training will prove useful for all athletes requiring fast adaptations and it can fit into training mesocycles due to its low time demands.

Key Words: Detraining, leg strength, quadriceps femoris, running, sprinting, time-course

\section{INTRODUCTION}

The capabilities of athletes to generate varied forceful movements and run explosively play a decisive role in many sports and can influence game outcomes (21). Therefore, the quest for designing effective sprint training programs is always relevant. Humans are able to achieve 
supramaximal speeds (5.6 - 8.4\% greater than their maximal sprinting capacity) while sprinting on downhill slopes, whereas sprinting on uphill slopes reduces the maximal achievable speed by 2.9 - 5.6\% $(19,35)$. Training under such conditions over a 6 -week period can result in improvements in maximal running speed (MRS) by $1.1 \%$ and step rate by $2.3 \%$ (36). However, when uphill and downhill stimuli have been combined in a single run (Figure 1), the beneficial effects have been greater. Furthermore, training for six to eight weeks on $3^{\circ}$ uphill and downhill sloping surfaces produced improvements for both MRS (from 3.5\% $5.9 \%$ ) and step rate (from $3.4 \%-7.4 \%)(32,34,36)$. These changes in MRS and step rate were linked to improvements in the maximal bilateral isometric force (7.1\%) and the force production rate $(24.7 \%)$ of the knee flexor muscles (33). Taken together, these results suggested that the combined uphill and downhill training method $(U+D)$ was more effective in improving MRS and the associated kinematic and kinetic characteristics of sprint running than an equivalent volume of horizontal or downhill training.

Despite these promising findings, the time course of mechanical and performance adaptations during uphill-downhill sprint training has not been monitored. Therefore, a chronological mapping of the progression rate of these changes will be extremely useful for scientific and training purposes. This will enable the determination of a timescale that could be used to identify the minimum training period needed for positive training adaptations. Moreover, monitoring of progression of the mechanical and performance adaptations during training could also provide an indication of the time course of the underlying neuromuscular adaptations. There is a great deal of evidence that supports neural mechanisms as the primary cause for the development of strength and power during the very initial stages of strength training (< 4-6 weeks) and muscular (mainly hypertrophic) mechanisms responsible for subsequent changes $(7,10,27,40)$.

Additionally, and of equal importance, the effects of detraining on the maintenance of the training adaptations and the degree of decline of the performance and mechanical changes achieved during training are relevant to understand the quality of the training stimulus. This is 
something that is of paramount importance for coaches and athletes planning training cycles and rest periods before competitions. Previous studies on strength training have shown that detraining periods equal to $50 \%$ of the training period display a time course of changes that is similar to but in the opposite direction to training, and that they result in losses in strength that are mainly explained by reductions in the neutral adaptation gained through training (9-11, 15, 29). However, the reduced values observed at the end of selected detraining periods for all the different variables across past studies are still higher than the pre-training values and, in many cases, they remain somewhat higher than values measured during the initial stages of training $(10-12,29,39)$. To date, there has not been a systematic monitoring study focused on the time course of adaptations and the effects of detraining after specialized sprint training programs. This is a considerable gap in the sprinting literature that the current study aims to address. This original contribution will be a point of reference for future short- to mid-term sprint training programs.

Therefore, the aims of this study were twofold: first, to monitor and approximate the minimum time needed to stimulate improvements in kinematic and strength characteristics during an uphill-downhill sprint training program; and second, to evaluate the effects of a detraining period on the same characteristics to establish the rate of decline and the maintenance period of the adaptations gained during training. The planned observations might also provide an insight into the contribution of different underlying mechanisms to the training adaptations.

\section{METHODS}

\section{Experimental Approach to the Problem}

Three training and one control group formed the sample population for this study. Participants were tested before and after a 6-week training period to measure kinematic characteristics of a $35 \mathrm{~m}$ horizontal sprint (MRS) and the mechanical characteristics of a 
maximum voluntary contraction (MVC) for knee extensor and flexor muscle groups. Additionally, to evaluate the progressive adaptations to the U+D sprint training over the training period, a progressive U+D group was also tested after two and four weeks of training. Finally, to evaluate the magnitude of detraining adaptations, a training-detraining $U+D$ group was tested once more after 3 -weeks of detraining. The decision to have two separate U+D groups rather than a single group was based on the need to keep the two time-related variables (progression and maintenance) independent from each other and minimize any influence of each upon the dependent variables of the other. The only instance where the two groups have been combined and referred as just $\mathrm{U}+\mathrm{D}$ group was when comparing the basic pre-post training effects (Tables 1,2$)$ with the other two groups $(\mathrm{H}$ and $\mathrm{C})$. All training and testing procedures were identical throughout the study and were supervised by the same research team.

\section{Subjects}

Twenty-eight physical education and sports science students participated in this study (age: $23.9 \pm 3.3$ years; height: $1.76 \pm 0.07 \mathrm{~m}$; mass: $74.96 \pm 11.20 \mathrm{~kg}$ ). All subjects were active in different sports, but none were sprinters; their mean maximum running speed was $8.77 \pm 0.68$ $\mathrm{m} \cdot \mathrm{s}^{-1}$. All subjects were asked to terminate any other systematic sport activity during the study, including resistance training. The study received ethical approval from the Carnegie Faculty Research Ethics Committee of Leeds Beckett University, who approved the details of the study, including consent documentation and information to subjects before commencement. In accordance with the Carnegie Faculty Research Ethics Committee's policies for use of human subjects in research, all subjects were informed of the benefits and possible risks associated with participation before taking part and informed of their right to withdraw at any point. All subjects were over the age of 18 and gave written informed consent to indicate their voluntary participation. Three training groups and a control group were formed in a random order through recruitment: the progressive uphill and downhill 
group $\left(\mathrm{P}_{-} \mathrm{U}+\mathrm{D}, \mathrm{n}=7\right)$, the training-detraining uphill-downhill group $\left(\mathrm{TD} \_\mathrm{U}+\mathrm{D}, \mathrm{n}=7\right)$, the horizontal group $(\mathrm{H}, \mathrm{n}=7)$ and the control group $(\mathrm{C}, \mathrm{n}=7)$.

\section{Procedures}

Training: A wooden uphill-downhill platform was used for training, $80 \mathrm{~m}$ long and $1.20 \mathrm{~m}$ wide, and was covered with a synthetic track surface. The platform consisted of 5 sections, arranged in the following order: (a) a 10-m horizontal section; (b) a 20-m uphill section at a $3^{\circ}$ slope; (c) a 10-m horizontal section; (d) a $20-\mathrm{m}$ downhill section at a $3^{\circ}$ slope; and (e) a 20 m horizontal section (Figure 1). The three groups were trained as follows: (a) U+D was trained on the uphill-downhill platform; (b) $\mathrm{H}$ was trained on the horizontal; and (c) $\mathrm{C}$ did not perform any training. After completion of a 20-min warm-up, both training groups performed $6 \times 80 \mathrm{~m}$ sprints at maximal intensity per session, three times a week, where the time between repetitions (4-6 $\mathrm{min}$ ) was sufficient for the subjects to recover fully. This training program continued until the fourth week, after which 1 repetition was added for both training groups for each of the remaining weeks (34). During the 3-week detraining period, both $\mathrm{U}+\mathrm{D}$ groups (P_U+D and TD_U+D) stopped all sprint training, maintained their normal activities but did not engage in any other form of training.

Testing: To assess the effects of training on the kinematic characteristics, a 35-m horizontal maximal sprint running test was used to measure MRS, step rate (SR), step length (SL), contact time (CT) and flight time (FT). The maximal bilateral isometric forces (MBIF) of the knee extensor and flexor muscles during an MVC were measured using a Universal leg extension machine connected to a force plate (9865, Kistler, Winterthur, Switzerland).

$35 \mathrm{~m}$ Sprint Testing: After completing a 20-min warm-up, the subjects performed 3 sprint runs over the $35 \mathrm{~m}$ distance using a standing start with a 6-8 min recovery period between repetitions along a $60 \mathrm{~m}$ indoor runway covered with a synthetic track surface ( $2.5 \mathrm{~m}$ wide). All testing was carried out under the same laboratory conditions at a similar time of day for each participant. The corridor was well lit, and the ambient temperature was $22^{\circ} \mathrm{C}$. The best 
of the three trials (based on MRS values) was selected for further analysis. A Kodak EktaPro digital 1000 Hi-Spec Motion Analyser System, sampling at $125 \mathrm{~Hz}$, was used to record sagittal plane movements during a full stride (two consecutive steps). Filming was performed with the camera placed at the end of the runway and $7.5 \mathrm{~m}$ from the performance plane such that its optical axis formed an angle of $90^{\circ}$ with the sagittal plane of running. Running speed should be near to its maximum $35 \mathrm{~m}$ after the start of a maximal sprint, as evidence from the literature has shown that MRS for non-elite sprinters is achieved between $30-40 \mathrm{~m} \mathrm{(8)}$. For the digitization process, a metal calibration frame was filmed such that the $\mathrm{x}$-axis was parallel to the horizontal and the y-axis was perpendicular to the horizontal.

Analysis of the video data: The video data were manually digitized to obtain kinematic data using motion analysis software (SIMI Motion, Munich). Seventeen segment endpoints were digitized for each subject and de Leva's (20) 14-segment body segment parameter model used to obtain data for the whole body center of mass (CM) and limb segments. Surface markers were used in the process of digitization when clearly visible. When the markers were not clearly visible, the operator identified the points for digitization based on superficial anatomical landmarks and an understanding of axes of rotation at the joints (3). The magnification tool in SIMI Motion was set at $400 \%$ to aid identification of the markers. The 14 segments were the head, trunk, upper arms, forearms, hands, thighs, lower legs and feet. For each running sequence, digitizing started five frames before the touchdown of the one foot and ended five frames after the touchdown of the opposite foot. This provided sufficient redundant data for smoothing. Touchdown and take-off were defined as the time instant at which the subject made and broke contact with the ground, respectively. The touchdown and take-off frames were identified through visual inspection by the same researcher who digitized all trials.

The step cycle had a starting point as the touchdown of one foot, continued through the flight phase and terminated at touchdown of the opposite foot. MRS corresponded to the mean CM horizontal velocity during one step whereas CT, FT, SL, SR were calculated according to the 
methods of Paradisis and Cooke (35). The video recordings were smoothed using a crossvalidated quintic spline (9).

To ensure reliability of the digitizing process, repeated digitizing ( 2 trials) of 1 sprinting step sequence at the same sampling frequency was performed by the same operator with an intervening period of 48 hours. The ICC $(3,1)$ values for the right upper arm y-coordinate, for the left foot $x$-coordinate and for CM $x$-velocity were $0.998,0.998$ and 0.952 , respectively.

Maximal isometric force - knee extensors: Three MVCs were performed by each subject where the best trial (based on peak force values) was selected for further analysis. Specifically, the subjects were seated on a leg extension machine, and were stabilized at the pelvis by a belt to restrict the movements to the lower extremity and avoid any assistance from the trunk muscles (hip angle $=110^{\circ}$, knee angle $=107^{\circ}$ ) $(17,22$ ). The leg extension machine was connected to the force plate by means of an adjustable chain. The subjects were instructed to react to an auditory signal by attempting to extend their knees as forcefully as possible and to maintain the maximal force for $2.5 \mathrm{~s}$. The force platform measured the vertical and the shear force production and consequently the MBIF for the knee extensors was defined as the highest value of the resultant force recorded during the MVC.

Maximal isometric force - leg flexors: For the measurement of the MBIF of the knee flexors, the subjects lay prone on the leg extension machine and were stabilized at the pelvis and ipsilateral thigh (hip angle $=180^{\circ}$, knee angle $\left.=140^{\circ}\right)(26)$ to prevent excessive movements of the lower extremity and avoid any assistance from the back muscles. The ICC $(3,1)$ values of the MBIF for extensors and flexors, obtained from a 48-h test-retest MVC measurement, were 0.988 and 0.985 respectively.

\section{Statistical analyses}


Two-way mixed (time [pre-post] x group) repeated measures analysis of variance (ANOVA) was used to establish whether there were any significant differences between the pre- and post-training tests, the training groups and any interaction effects for each variable. Additionally, 1-way repeated-measures ANOVA was used to establish whether there were any significant differences between the pre-, week 2 , week 4 , post-training, and detraining period in the $\mathrm{P}_{-} \mathrm{U}+\mathrm{D}$ and $\mathrm{TD} \_\mathrm{U}+\mathrm{D}$ groups. In the event of significant main effects or interactions, post-hoc Tukey's HSD or Tukey-Kramer (for uneven groups / variances) tests were used to test all pairwise comparisons. The significance level for all tests was set at $P<$ 0.05. In addition, effect sizes using Cohen's $d$ (4) (effect sizes defined as either small: $d=$ $0.20-0.49$, medium: $d=0.50-0.79$, large: $d=0.80-1.19$, very large: $d=1.20-1.99$, or huge: $d \geq 2.0$ ), the magnitude of the mean \pm 1 standard deviation (SD) differences between testing sessions $(\mathrm{M} \Delta)$ and the $95 \%$ confidence intervals $(95 \% \mathrm{CI})$ and power estimation were used for data interpretation.

\section{RESULTS}

\section{Effects of different training methods}

Kinematic characteristics: The statistical analysis for the MRS revealed a significant time effect $\left(F=4.586, P<0.05, \eta_{\mathrm{p}}{ }^{2}=0.155\right.$, power $\left.=0.539\right)$ and an interaction effect between time and training group $\left(F=9.124, P<0.05, \eta_{\mathrm{p}}^{2}=0.422\right.$, power $\left.=0.958\right)$. The post-hoc Tukey's HSD comparisons showed pre-post training differences at the 0.05 level for the U+D group ( $\mathrm{M} \Delta=0.32 \pm 0.24 \mathrm{~m} \cdot \mathrm{s}^{-1}, 95 \% \mathrm{CI}=0.042$ to $0.272 \mathrm{~m} \cdot \mathrm{s}^{-1}, d=0.48$ ). All other comparisons showed no differences. After U+D training, 13 of the 14 subjects increased MRS (range $\left.=0.09-0.89 \mathrm{~m} \cdot \mathrm{s}^{-1}\right)$. The overall findings are presented in Table 1.

The analysis for SR revealed a significant interaction effect between time and training group $\left(F=3.579, P<0.05, \eta_{\mathrm{p}}{ }^{2}=0.223\right.$, power $\left.=0.609\right)$. The post-hoc Tukey's HSD comparisons 
showed pre-post training differences at the 0.05 level for the $\mathrm{U}+\mathrm{D}$ group $(\mathrm{M} \Delta=0.13 \pm 0.18$ $\mathrm{Hz}, 95 \% \mathrm{CI}=0.006$ to $0.126 \mathrm{~Hz}, d=0.67)$. All other comparisons showed no differences. After U+D training, 10 of the 14 subjects increased SR (range $=0.11-0.43 \mathrm{~Hz}$ ). CT and FT did not change. Finally, SL remained unaltered for the U+D group, and all the analyzed variables for the $\mathrm{H}$ and $\mathrm{C}$ groups did not change (Table 1).

Kinetic characteristics: The statistical analysis for the MBIF of leg extensors revealed a significant time effect $\left(F=7.550, P<0.05, \eta_{\mathrm{p}}{ }^{2}=0.232\right.$, power $\left.=0.752\right)$ and an interaction effect between time and training group $\left(F=7.007, P<0.05, \eta_{\mathbf{p}}{ }^{2}=0.359\right.$, power $\left.=0.893\right)$. The post-hoc Tukey-Kramer comparisons showed pre-post training differences at the 0.05 level for the $\mathrm{U}+\mathrm{D}$ group $(\mathrm{M} \Delta=470 \pm 432 \mathrm{~N}, 95 \% \mathrm{CI}=221$ to $719 \mathrm{~N}, d=0.95)$. All other comparisons showed no differences. After U+D training, 12 of the 14 subjects increased the MIF of the knee extensors (range $=106-1293 \mathrm{~N}$ ). The overall findings are presented in Table 2. Finally, the statistical analysis for the MBIF of the knee flexors revealed no significant main or interaction effects (Table 1).

\section{Progressive adaptations of the $\mathbf{U}+\mathrm{D}$ training}

Kinematic Variables: The statistical analysis for MRS revealed a significant main effect for time $\left(F=9.894, P<0.05, \eta_{\mathrm{p}}{ }^{2}=0.623\right.$, power $\left.=0.990\right)$. The post-hoc Tukey's HSD comparisons showed that the post-training MRS was higher than the pre-training value $(4.6 \%$, $P<0.05, \mathrm{M} \Delta=0.40 \pm 0.25 \mathrm{~m} \cdot \mathrm{s}^{-1}, 95 \% \mathrm{CI}=0.171$ to $\left.0.634 \mathrm{~m} \cdot \mathrm{s}^{-1}, d=1.61\right)$, week $2(7.3 \%, P$ $<0.05, \mathrm{M} \Delta=0.62 \pm 0.32 \mathrm{~m} \cdot \mathrm{s}^{-1}, 95 \% \mathrm{CI}=0.326$ to $\left.0.917 \mathrm{~m} \cdot \mathrm{s}^{-1}, d=1.93\right)$ and week $4(6.2 \%$, $P<0.05, \mathrm{M} \Delta=0.53 \pm 0.15 \mathrm{~m} \cdot \mathrm{s}^{-1}, 95 \% \mathrm{CI}=0.396$ to $0.667 \mathrm{~m} \cdot \mathrm{s}^{-1}, d=3.58$ ) values (Table 2, Figure 2E). Regarding SR (Table 2), repeated measures ANOVA revealed a significant time effect $\left(F=5.925, P<0.05, \eta_{\mathrm{p}}{ }^{2}=0.497\right.$, power $\left.=0.902\right)$ with the post-hoc Tukey's HSD comparisons showing a difference between the week 4 and post-training tests $(9.1 \%, P<$ $0.05, \mathrm{M} \Delta=0.36 \pm 0.28 \mathrm{~Hz}, 95 \% \mathrm{CI}=0.095$ to $0.616 \mathrm{~Hz}, d=1.27$ ) (Figure 2C). Differences 
were also noted for the CT changes $\left(F=5.905, P<0.05, \eta_{\mathrm{p}}{ }^{2}=0.498\right.$, power $\left.=0.903\right)$; the post-hoc tests showed that $\mathrm{CT}$ for week 4 was higher than the pre-training $(9.9 \%, P<0.05$, $\mathrm{M} \Delta=12 \pm 7 \mathrm{~ms}, 95 \% \mathrm{CI}=5$ to $19 \mathrm{~ms}, d=1.68)$ and post-training values $(13.4 \%, P<0.05$, $\mathrm{M} \Delta=16 \pm 9 \mathrm{~ms}, 95 \% \mathrm{CI}=7$ to $24 \mathrm{~ms}, d=1.61)$. Finally, the statistical analysis did not reveal any changes for SL and FT (Table 2).

Kinetic Variables: The statistical analysis for the MBIF of the knee extensors revealed a significant main effect for time $\left(F=4.346, P<0.05, \eta_{\mathrm{p}}{ }^{2}=0.420\right.$, power $\left.=0.782\right)$. The Tukey's HSD post-hoc tests showed that the post-training MBIF of the knee extensors was higher than pre-training $(20.4 \%, P<0.05, \mathrm{M} \Delta=468 \pm 545 \mathrm{~N}, 95 \% \mathrm{CI}=-36$ to $972 \mathrm{~N}, d=$ $0.86)$ and week 2 values $(21.8 \%, P<0.05, \mathrm{M} \Delta=495 \pm 388 \mathrm{~N}, 95 \% \mathrm{CI}=136$ to $854 \mathrm{~N}, d=$ 1.28) (Table 2, Figure 3). Finally, the statistical analysis for the MBIF of the knee flexors revealed no significant main effects (Table 2, Figure 3).

\section{Detraining effects of the $U+D$ training}

Kinematic Variables: The statistical analysis for MRS revealed a significant main effect for time $\left(F=6.560, P<0.05, \eta_{\mathrm{p}}{ }^{2}=0.522\right.$, power $\left.=0.820\right)$. The Tukey's HSD post-hoc comparisons showed that the post-training MRS was higher than the pre-training values $\left(2.8 \%, P<0.05, \mathrm{M} \Delta=0.25 \pm 0.23 \mathrm{~m} \cdot \mathrm{s}^{-1}, 95 \% \mathrm{CI}=-0.020\right.$ to $\left.0.250 \mathrm{~m} \cdot \mathrm{s}^{-1}, d=1.10\right)$ but not different from the detraining scores (Figure 2F). Finally, the statistical analysis did not reveal any changes for all the other variables (Table 3, Figure 2).

Kinetic Variables: The statistical analysis for the MBIF of the knee extensors revealed a significant main effect for time $\left(F=9.280, P<0.05, \eta_{\mathrm{p}}{ }^{2}=0.607\right.$, power $\left.=0.932\right)$. The Tukey's HSD post-hoc tests showed that the post-training $(21.6 \%, P<0.05, \mathrm{M} \Delta=472 \pm 327$ $\mathrm{N}, 95 \% \mathrm{CI}=170$ to $775 \mathrm{~N}, d=1.45)$ and detraining values $(12.3 \%, P<0.05, \mathrm{M} \Delta=269 \pm$ $231 \mathrm{~N}, 95 \% \mathrm{CI}=55$ to $482 \mathrm{~N}, d=1.16$ ) for the MBIF of the knee extensors were higher than 
the pre-training scores (Table 3, Figure 3). Finally, the statistical analysis for the MBIF of leg flexors revealed no significant main effects (Table 3, Figure 3).

\section{DISCUSSION}

Overall, the cross-group results emphasize the efficacy and superiority of the uphill-downhill sprint training as six weeks of training on slopes of $3^{\circ}$ improved key kinematic characteristics, whereas no changes were observed for the $\mathrm{H}$ and $\mathrm{C}$ groups. In particular, the 3.7\% increase in MRS for the U+D training group was accompanied by increases in SR (3.1\%), which can be attributed to decreases in the two time-dependent variables, CT (2.5\%) and FT (3.4\%). A main difference between this study and our previous studies using the same training regimen $(32,33)$ is its shorter duration (six weeks instead of eight), which interestingly still provided a sufficient period for performance adaptations to emerge. This is an important finding mainly from a coaching perspective as it promises a more time-efficient management of sprint training mesocycles.

The rationale for the superiority of the $\mathrm{U}+\mathrm{D}$ training against a range of other training methods, including horizontal sprinting, has been well documented previously and so will not be discussed at length here $(33,34,36)$. In short, the combined effect of submaximal and supramaximal sprinting in a single run appears to instigate unique mechanical stimuli which over time support leg muscles to become more effective when performing sprinting movements on horizontal surfaces. However, there is a need to discuss the leg strength data, as an additional training benefit, observed in this study. In particular, the U+D training increased maximum strength of the knee extensor muscles by $21 \%$, as measured through an MVC bilateral test. Additionally, a group trend for a 3.4\% non-significant change was observed for the maximum strength of the knee flexors after the $U+D$ training, with 10 out of 14 subjects showing improvements of $12.2 \pm 10.6 \%$. It is therefore evident that six weeks of uphill-downhill sprint training had beneficial effects on maximum strength for the knee 
extensor muscles. Although our previous study (33) showed an increase (10.6\%) in the bilateral isometric force of the knee flexors after eight weeks of $U+D$ training, the increase in isometric knee extensor strength measured here is a new observation, providing additional insight into the range of adaptation mechanisms related to $U+D$ training.

The lack of $\mathrm{U}+\mathrm{D}$ group changes for the knee flexors during training, after training and during detraining is interesting given the main role of the hamstrings in sprinting (16). However, this observation should not be considered as a failure of the training regimen to condition the hamstring muscles, but rather as a limitation of the testing tool to detect positive conditioning consistently for all participants. This also applies to our previous studies where the reverse had occurred, i.e., detecting changes in knee flexors but not knee extensors. Although isometric testing has been correlated strongly with sprinting performance (2) and has detected strength changes derived from sprint training (14), employing an isometric test to measure limb strength has some advantages but also some limitations in assessing strength in a holistic and representative manner, as research has shown greater relationships between explosive performance and dynamic strength tests against isometric strength assessments (31). The force exerted on the dynamometer is a function of a number of fundamental internal and external factors, which also vary between individuals. So, although an isometric test is a robust and reproducible way to measure strength specific to a single joint position, it does on the other hand not represent the expression of joint movement patterns specific to the competitive activity, in this case sprint running where for example in competitive sprinting the hip knee joint extends at speeds over $1000^{\circ} \cdot \mathrm{s}^{-1}(1)$. Results from such an isometric test are also affected by how individuals express their strength during the MVC because of differences in internal neuro-mechanical properties between participants, with some individuals responding to the isometric conditions more favorably than others. Apart from between-participant variability, there is also within-participant variability when performing MVC tests, and both types of variability are affected by the different contributions of the adjacent joints and the individual strategies adopted during a test with intra-trial differences 
$(23,30)$. An additional factor that might have prevented the detection of possible strength changes for flexors could be the testing posture used for the hamstrings, mainly testing their flexor capacity but not their functional role as hip extensors in sprinting. By contrast, though not ideal, the set-up for the knee extensors provided a better basis to test the quadriceps femoris given their extensor role during sprinting and at angles (hip and knee) within the range of those observed during the late recovery phase of sprinting, where most of the electrical activity of this muscle group has been recorded $(18,25,41)$. Despite the limitations of the isometric testing acknowledged above, there is no doubt that training on the platform provides strong stimuli for adaptation processes that result in the beneficial conditioning of key leg muscles, with the knee extensors benefiting in this particular study. Albeit speculative at this stage, these adaptations should be related with the positive changes in the sprinting performance. Indeed, the pre-post improvements in MRS for the $U+D$ group $(n=14)$ were correlated with improvements in the MBIF for the knee extensors $(r=0.49, P<0.05)$.

In terms of the time course changes for the $\mathrm{U}+\mathrm{D}$ training group, the results from all tested parameters indicate that the beneficial effects of the uphill-downhill sprint training become apparent after six weeks of training. The data revealed a non-significant decline in MRS in week 2 due to shifts in other related variables (e.g. increases in CT). This initial decline can be explained as a result of adjustments to the new training stimulus which was unique for all participants as they had not previously experienced a similar type of exercise pattern, i.e. high intensity sprinting on slopes. Following that time point, the group MRS showed reached a significant improvement by week 6 . In particular, the group MRS values at week 6 were higher than all previous measurements (pre-training, weeks 2 and 4) (Figure 2E). Some group changes were also observed for SR and CT, with post-training values showing improvements compared with those of week 4, but it would be arbitrary to attribute the whole group MRS alterations throughout the training period to a particular pattern of kinematic changes given the variability of responses shown across the participants in the $U+D$ groups. Although group analyses provide an understanding of some common denominators for training adaptations, it 
should be acknowledged that individuals might experience different magnitudes and types of adaptations, unique to them, which on occasion are not fully aligned with group changes. In this study, although all participants improved their sprinting performance by week 6 , there was some variability in the changes in kinematics leading to these improvements, as for a small subgroup the primary change associated with these improvements was an increase in SL rather than changes in temporal characteristics. However, the greatest individual velocity improvements within the whole U+D group $(n=14)$ were achieved only when SR and SL improved concurrently. For instance, there were six participants who improved both SR and SL by a mean of $4.1 \%$ and $2.5 \%$, respectively, and as a result achieved a mean $6.3 \%$ increase in MRS. On the other hand, the remaining seven participants improved either SR or SL, but not both, achieved only a $2.5 \%$ increase in MRS post-training. Undeniably, the results of the present study show that the minimum period to improve sprinting speed through $U+D$ training in a group of young and active adults is six weeks or 18 high intensity training sessions spaced apart with at least 48-h intervals. This spacing seems appropriate to allow recovery for the key muscles involved in training, whereas shorter intervals $(<48-\mathrm{h})$ might have had a detrimental effect on performance because of fatigue (37). This is the key message to specialists wishing to employ the same training technique. It is also a useful finding for all those interested in the changes occurring during the early stages of sprint training for similar populations, irrespective of the use of slopes in the training program.

The time MBIF data series for the knee extensors followed a very similar pattern to the one for MRS with strength at week 6 exceeding the group strength for pre-training and week 2 (Figure 3). This parallel trend in the knee extensor strength data (pre-post MRS-MBIF changes correlated strongly: $r=0.88, P<0.05)$, which corroborates the notion of the beneficial conditioning of this muscle group as a result of the U+D training and their important function in sprint running. Although most of the attention in literature and practice has been placed historically on the hamstring-sprinting relationship, it should be acknowledged that the quadriceps femoris play a crucial role in sprinting performance both 
from an energy absorption and generation perspective (13). These parallel changes in maximum strength and MRS imply the influence of the same neuromuscular mechanisms in both cases (knee extension and sprinting), with respect to the knee extensor muscles. The exact origin and nature of these mechanisms of adaptation are beyond the scope of the present study. However, taking into account the type of training (anisometric with high-velocity muscle actions), its duration, the changes in the temporal characteristics, and knowledge of time-course adaptations alongside evidence of associations between fast motor units and explosive movements (24), we hypothesize that an increased neural input to the muscles, perhaps supported by other non-hypertrophic muscular adaptations, was the primary mechanism for the training adaptations $(6,7,10,38)$.

Regarding the detraining period, it seems that the sprinting performance improvements due to a 6-week training program were by and large maintained for the $\mathrm{U}+\mathrm{D}$ group as the kinematic data obtained at the end of the 3-week detraining period did not display any changes compared with the post-training values. Obviously, some individuals exhibited a slightly varied pattern as with the pre-post and time-course data series, but group findings indicate clearly that a detraining period equal in length to $50 \%$ of the training duration on the uphilldownhill platform produced no changes in running speed. The rate of decline in MRS $(1.3 \%)$ is considered as moderate and its maintenance (98.7\%) as adequate given the pre-training values (Figure 2F). A retraining period after detraining could have probably provided a better picture of the maintenance of adaptations. It seems that the absence of a decline in running speed observed during detraining was due to an equally small decline in SR $(0.7 \%)$ for four of the eight participants. As with the pre-post and time-course changes the group detraining values for the MBIF of the knee extensors followed a similar pattern to the MRS values. In particular, the MBIF values were not different from the post training values but were higher $(12.3 \%)$ than the pre-training values (Figure 3). It seems that the detraining period caused only a moderate decline in the maximum knee strength extensors that allowed the maintenance of strength values higher than the pre-training values. 
These findings are in agreement with past studies that showed a detraining duration equal to $50 \%$ of the training period, as in the current study, caused a progressive decline in strength at a similar rate to the increase in strength with training. On many occasions in past research, the values observed at the end of selected detraining periods for several strength and power parameters were still higher than the pre-training ones $(10-12,29,39)$. In addition, the losses due to the termination of training were smaller when the training program included eccentric actions (5). The latter applies appropriately to the current findings since uphill-downhill sprint running is a combination of powerful concentric and eccentric actions, with the downhill segment instigating high eccentric stretching velocities because of supramaximal sprinting on the $3^{\circ}$ slope. In previous studies, the losses in strength had been accompanied by losses in cross-sectional area, muscle fiber area and decreased electromyographic activity $(10,11,15,28)$. Without similar measurements in the present study it is not possible to characterize the specific effects of detraining but, as has been speculated above, the assumption is that neural adaptations were gradually lost during the 3-week detraining period. However, the unique finding here is that the positive strength and more importantly sprint performance changes after training were maintained to a considerable extent during the detraining period. This information is extremely valuable as, to our knowledge, this is the first study examining the effects of detraining on sprint running performance. Finally, the modest changes in the detraining period suggest that detraining values could easily reach posttraining values again with a short period of retraining, although this remains to be established empirically.

In conclusion, the findings of the study demonstrate clearly the beneficial effects of uphilldownhill sprint training on kinematic parameters that are linked with sprinting performance. The increases in MRS were supported by improvements in SR, with increases in SL as a secondary mechanism of MRS increases for a small number of participants. The improvements in running speed were accompanied by improvements in the absolute strength of the knee extensor muscles. The minimum period needed to produce positive group effects 
on the kinematic parameters and knee extensor strength is six weeks with 3 training sessions per week. The rate of decline in sprinting performance and leg strength during three weeks of detraining was moderate with a very good standard of performance maintained nine weeks after the commencement of training. Evidence from the literature would support the assumption that the kinematic and strength changes observed during the course of the training and detraining imply the influence of the same neuromuscular mechanisms on both movements with the neural component being possibly the key contributing factor. Finally, it was observed that the training and detraining effects on all tested variables also depend on the individual responses to the training and detraining stimuli.

\section{PRACTICAL APPLICATIONS}

The study offers original and pragmatic guidance to coaches and athletes. First, it showcases the advantages of uphill-downhill training against more conventional sprint running training methods. The results show that short duration programs of six weeks can make a difference in sprinting performance in populations who regularly take part in a range of sports. Such training programs have multiple applications beyond track and field for the strength and conditioning professional as, for example, it can a serve as a main component during a precompetition mesocycle for college soccer, American football or other games involving multiple sprints. Because of its low demand in terms of time (each training sessions is anticipated to last about 1 hour) and commitment (three times per week), such training can be used alongside other ongoing training practices and sessions. However, participants in the current study refrained from any other systematic training. The beneficial effects of training can be maintained for a reasonable time with the potential to be regained fully during succeeding mesocycles of duration of up to three weeks, where the focus might need to be on other physical qualities or technique and tactics. The appeal of this training method is based not only on the fact that improvements in sprinting performance can take place within a short 
period of time, but also on the general conditioning that is provided to key leg muscles through a composite stimulus incorporating concentric and eccentric loading in single supramaximal sprints. 


\section{REFERENCES}

1. Bissas, A, Walker, J, Tucker, C, Paradisis, G, and Merlino, S. Biomechanical Report for the IAAF World Championships 2017: 100 m Men's. London: IAAF, 2018.

2. Brady, CJ, Harrison, AJ, Flanagan, EP, Haff, GG, and Comyns, TM. The Relationship Between Isometric Strength and Sprint Acceleration in Sprinters. Int J Sports Physiol Perform 1-25, 2019. doi: 10.1123/ijspp.2019-0151

3. Challis, J, Bartlett, R., and Yeadon, M. Image-based motion analysis. In: Biomechanical Analysis of Movement in Sport and Exercise. Bartlett, R., ed. Leeds: BASES, 1997. pp. 7-30

4. Cohen, J, Wassertheil, S, and Cohen, J. Statistical Power Analysis for the Behavioral Sciences. 2nd ed. Hillsdale, NJ: Lawrence Erlbaum, 1988

5. Colliander, EB and Tesch, PA. Effects of detraining following short term resistance training on eccentric and concentric muscle strength. Acta Physiol Scand 144: 23-29, 1992. doi: 10.1111/j.1748-1716.1992.tb09263.x

6. Van Cutsem, M, Duchateau, J, and Hainaut, K. Changes in single motor unit behaviour contribute to the increase in contraction speed after dynamic training in humans. J Physiol 513: 295-305, 1998. doi: 10.1111/j.1469-7793.1998.295by.x

7. DeFreitas, JM, Beck, TW, Stock, MS, Dillon, MA, and Kasishke, PR. An examination of the time course of training-induced skeletal muscle hypertrophy. Eur J Appl Physiol 111: 2785-2790, 2011. doi: 10.1007/s00421-011-1905-4

8. Gajer, B, Thepaut-Mathieu, C, and Lehenaff, D. Evolution of stride and amplitude during course of the $100 \mathrm{~m}$ event in athletics. New Stud Athl 14: 43-50, 1999.

9. Giakas, G and Baltzopoulos, V. A comparison of automatic filtering techniques applied to biomechanical walking data. $J$ Biomech 30: 847-850, 1997. doi: 
$10.1016 / \mathrm{S} 0021-9290(97) 00042-0$

10. Häkkinen, $\mathrm{K}$ and Komi, P V. Electromyographic changes during strength training and detraining. Med Sci Sports Exerc 15: 455-60, 1983.

11. Häkkinen, K, Komi, P V, and Tesch, PA. Effect of combined concentric and eccentric strength training and detraining on force-time, muscle fibre and metabolic characteristics of long extensor muscles. Scand J Sport Sci 3: 50-58, 1981.

12. Häkkinen, K, Komi, PV, and Alén, M. Effect of explosive type strength training on isometric force- and relaxation-time, electromyographic and muscle fibre characteristics of leg extensor muscles. Acta Physiol Scand 125: 587-600, 1985. doi: 10.1111/j.1748-1716.1985.tb07760.x

13. Handsfield, GG, Knaus, KR, Fiorentino, NM, Meyer, CH, Hart, JM, and Blemker, SS. Adding muscle where you need it: non-uniform hypertrophy patterns in elite sprinters. Scand J Med Sci Sports 27: 1050-1060, 2017. doi: 10.1111/sms.12723

14. Harridge, SDR, Bottinelli, R, Canepari, M, Pellegrino, M, Reggiani, C, Esbjörnsson, M, Balsom, PD, and Saltin, B. Sprint training, in vitro and in vivo muscle function, and myosin heavy chain expression. J Appl Physiol 84: 442-449, 1998. doi: 10.1152/jappl.1998.84.2.442

15. Houston, ME, Froese, EA, Valeriote, SP, Green, HJ, and Ranney, DA. Muscle performance, morphology and metabolic capacity during strength training and detraining: a one leg model. Eur J Appl Physiol Occup Physiol 51: 25-35, 1983. doi: 10.1007/BF00952534

16. Howard, RM, Conway, R, and Harrison, AJ. Muscle activity in sprinting: a review. Sport Biomech 17: 1-17, 2018. doi: 10.1080/14763141.2016.1252790

17. Komi, P V., Viitasalo, JT, Rauramaa, R, and Vihko, V. Effect of isometric strength 
training on mechanical, electrical, and metabolic aspects of muscle function. Eur $J$ Appl Physiol Occup Physiol 40: 45-55, 1978. doi: 10.1007/BF00420988

18. Kuitunen, S, Komi, P V., and Kyröläinen, H. Knee and ankle joint stiffness in sprint running. Med Sci Sports Exerc 34: 166-173, 2002. doi: 10.1097/00005768200201000-00025

19. Kunz, H and Kaufmann, DA. Biomechanics of hill sprinting. Track Tech 82: 26032605, 1981.

20. De Leva, P. Adjustments to zatsiorsky-seluyanov's segment inertia parameters. $J$ Biomech 29: 1223-1230, 1996. doi: 10.1016/0021-9290(95)00178-6

21. Little, T and Williams, AG. Specificity of Acceleration, Maximum Speed, and Agility in Professional Soccer Players. J Strength Cond Res 19: 76, 2005. doi: $10.1519 / 14253.1$

22. Lord, JP, Aitkens, SG, McCrory MA, and Bernauer, EM. Isometric and isokinetic measurement of hamstring and quadriceps strength. Arch Phys Med Rehab 73: 324330, 1992. doi: 10.1016/0003-9993(92)90004-G

23. McHugh, MP and Hogan, DE. Effect of knee flexion angle on active joint stiffness. Acta Physiol Scand 180: 249-254, 2004. doi: 10.1046/j.0001-6772.2003.01240.x

24. Meijer, JP, Jaspers, RT, Rittweger, J, Seynnes, OR, Kamandulis, S, Brazaitis, M, Skurvydas, A, Pišot, R, Šimunič, B, Narici, M V., and Degens, H. Single muscle fibre contractile properties differ between body-builders, power athletes and control subjects. Exp Physiol 100: 1331-1341, 2015. doi: 10.1113/EP085267

25. Mero, A and Komi, P V. EMG, Force, and Power Analysis of Sprint-Specific Strength Exercises. $J$ Appl Biomech 10: 1-13, 1994. doi: 10.1123/jab.10.1.1

26. Mero, A, Komi, P V., and Gregor, RJ. Biomechanics of Sprint Running: A Review. 
Sports Med 13: 376-392, 1992. doi: 10.2165/00007256-199213060-00002

27. Moritani, T and deVries, HA. Neural factors versus hypertrophy in the time course of muscle strength gain. Am J Phys Med 58: 115-30, 1979.

28. Mujika, I and Padilla, S. Muscular characteristics of detraining in humans. Med Sci Sports Exerc 33: 1297-303, 2001. doi: 10.1097/00005768-200108000-00009

29. Narici, M V., Roi, GS, Landoni, L, Minetti, AE, and Cerretelli, P. Changes in force, cross-sectional area and neural activation during strength training and detraining of the human quadriceps. Eur J Appl Physiol Occup Physiol 59: 310-319, 1989. doi: $10.1007 / \mathrm{BF} 02388334$

30. Nozaki, D, Nakazawa, K, and Akai, M. Uncertainty of knee joint muscle activity during knee joint torque exertion: the significance of controlling adjacent joint torque. J Appl Physiol 99: 1093-1103, 2005. doi: 10.1152/japplphysiol.00365.2005

31. Nuzzo, JL, McBride, JM, Cormie, P, and McCaulley, GO. Relationship Between Countermovement Jump Performance and Multijoint Isometric and Dynamic Tests of Strength. J Strength Cond Res 22: 699-707, 2008. doi:

10.1519/JSC.0b013e31816d5eda

32. Paradisis, GP, Bissas, A, and Cooke, CB. Combined uphill and downhill sprint running training is more efficacious than horizontal. Int J Sports Physiol Perform 4: 229-243, 2009. doi: 10.1123/ijspp.4.2.229

33. Paradisis, GP, Bissas, A, and Cooke, CB. Changes in Leg Strength and Kinematics with Uphill — Downhill Sprint Training. Int J Sports Sci Coach 8: 543-556, 2013. doi: $10.1260 / 1747-9541.8 .3 .543$

34. Paradisis, GP, Bissas, A, and Cooke, CB. Effect of Combined Uphill-Downhill Sprint Training on Kinematics and Maximum Running Speed in Experienced Sprinters. Int J 
Sports Sci Coach 10: 887-898, 2015. doi: 10.1260/1747-9541.10.5.887

35. Paradisis, GP and Cooke, CB. Kinematic and postural characteristics of sprint running on sloping surfaces. J Sports Sci 19: 149-159, 2001. doi:

$10.1080 / 026404101300036370$

36. Paradisis, GP and Cooke, CB. The effects of sprint running training on sloping surfaces. J Strength Cond Res 20: 767-777, 2006. doi: 10.1519/R-16834.1

37. Parra, J, Cadefau, JA, Rodas, G, Amigó, N, and Cussö, R. The distribution of rest periods affects performance and adaptations of energy metabolism induced by highintensity training in human muscle. Acta Physiol Scand 169: 157-165, 2000. doi: 10.1046/j.1365-201x.2000.00730.x

38. Sale, DG. Neural Adaptation to Strength Training. In: Strength and Power in Sport.2008. pp. 281-314

39. Shima, N, Ishida, K, Katayama, K, Morotome, Y, Sato, Y, and Miyamura, M. Cross education of muscular strength during unilateral resistance training and detraining. Eur J Appl Physiol 86: 287-94, 2002. doi: 10.1007/s00421-001-0559-z

40. Del Vecchio, A, Casolo, A, Negro, F, Scorcelletti, M, Bazzucchi, I, Enoka, R, Felici, F, and Farina, D. The increase in muscle force after 4 weeks of strength training is mediated by adaptations in motor unit recruitment and rate coding. J Physiol 597: 1873-1887, 2019. doi: 10.1113/JP277250

41. Wiemann, K and Tidow, G. Relative activity of hip and knee extensors in sprinting implications for training. New Stud Athl 10: 29-49, 1995. 
Table 1. Pre and post training values (Mean \pm SD and $\%$ differences) of the kinematic characteristics and the maximum bilateral isometric force for the leg extensor and flexor muscles of all groups $(\mathrm{N}=28)$.

Table 2. Mean \pm SD of the kinematic characteristics and the maximum bilateral isometric force for the leg extensor and flexor muscles in pre-, week 2, week 4, and post-tests of the progressive uphill-downhill group ( $\mathrm{N}=7)$.

Table 3. Mean \pm SD of the kinematic characteristics and the maximum bilateral isometric force for the leg extensor and flexor muscles in pre-, post-training and after the detraining period of the training-detraining uphill-downhill group $(\mathrm{N}=7)$. 
Figure 1. The uphill-downhill platform: 10-m horizontal, 20-m uphill at $3^{\circ}, 10-\mathrm{m}$ horizontal, 20-m downhill at $3^{\circ}, 20-\mathrm{m}$ horizontal.

Figure 2. Time series kinematic data of relative changes for the Progressive (left column) and Training-Detraining (right column) U+D groups with the $100 \%$ values corresponding to pre-training values. "Significantly different from pre-training $(P<0.05)$ and

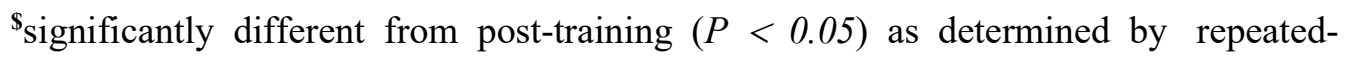
measures analysis of variance and Tukey's HSD post-hoc tests.

Figure 3. Time series strength data of relative MBIF changes for the Progressive (left column) and Training-Detraining (right column) U+D groups with the $100 \%$ values corresponding to pre-training values. "Significantly different from pre-training $(P<$ $0.05)$ and ${ }^{\$}$ significantly different from post-training $(P<0.05)$ as determined by repeated-measures analysis of variance and Tukey's HSD post-hoc tests. 
Table 1. Pre and post training values (Mean $\pm \mathrm{SD}$ and $\%$ differences) of the kinematic characteristics and the maximum bilateral isometric force for the leg extensor and flexor muscles of all groups $(\mathrm{N}=28)$.

\begin{tabular}{ccccccccc} 
& & MRS $\left(\mathrm{m} \cdot \mathrm{s}^{-1}\right)$ & SR $(\mathrm{Hz})$ & SL $(\mathrm{m})$ & CT $(\mathrm{ms})$ & FT $(\mathrm{ms})$ & MBIF_LEM $(\mathrm{N})$ & MBIF_LFM $(\mathrm{N})$ \\
\hline & Pre & $8.75 \pm 0.72$ & $4.21 \pm 0.21$ & $2.08 \pm 0.17$ & $121 \pm 12$ & $117 \pm 13$ & $2241.75 \pm 488.92$ & $1341.93 \pm 274.69$ \\
$\mathbf{U}+\mathbf{D}$ & Post & $9.07 \pm 0.64^{*}$ & $4.34 \pm 0.18^{*}$ & $2.10 \pm 0.14$ & $118 \pm 9$ & $113 \pm 13$ & $2711.81 \pm 497.56^{*}$ & $1387.69 \pm 263.65$ \\
& $\Delta \%$ & 3.7 & 3.1 & 1.0 & -2.5 & -3.4 & 21 & 3.4 \\
& Pre & $8.80 \pm 0.23$ & $4.25 \pm 0.11$ & $2.07 \pm 0.05$ & $116 \pm 8$ & $120 \pm 10$ & $2420.34 \pm 510.64$ & $1247.87 \pm 296.97$ \\
$\mathbf{H}$ & Post & $8.91 \pm 0.33$ & $4.30 \pm 0.16$ & $2.07 \pm 0.05$ & $113 \pm 7$ & $120 \pm 11$ & $2461.18 \pm 541.01$ & $1270.26 \pm 295.08$ \\
& $\Delta \%$ & 1.3 & 1.2 & 0 & -2.6 & 0 & 1.7 & 1.8 \\
& Pre & $8.77 \pm 0.94$ & $4.43 \pm 0.19$ & $1.98 \pm 0.16$ & $115 \pm 5$ & $110 \pm 8$ & $2325.54 \pm 177.74$ & $1233.13 \pm 309.98$ \\
C & Post & $8.64 \pm 0.96$ & $4.38 \pm 0.21$ & $1.97 \pm 0.17$ & $117 \pm 6$ & $111 \pm 10$ & $2332.93 \pm 160.56$ & $1226.90 \pm 304.29$ \\
& $\Delta \%$ & -1.5 & -1.1 & -0.5 & 1.7 & -0.9 & 0.3 & -0.5 \\
\hline
\end{tabular}

*Significantly different from pre-training $(P<0.05)$ as determined by repeated-measures analysis of variance and Tukey's HSD and Tukey-Kramer post-hoc tests. Abbreviations: $\mathrm{U}+\mathrm{D}=$ combined uphill and downhill training group $(\mathrm{n}=14), \mathrm{H}=$ horizontal training group $(\mathrm{n}=7), \mathrm{C}=$ control group $(\mathrm{n}=7), \Delta \%=$ percentage difference between pre and post training values, $\mathrm{MRS}=$ maximum running speed, $\mathrm{SR}=$ step rate, $\mathrm{SL}=$ step length, $\mathrm{CT}=$ contact time, FT = flight time, MBIF_LEM = maximal bilateral isometric force for the leg extensor muscles, MBIF_LFM $=$ maximal bilateral isometric force for the leg flexor muscles. 
Table 2. Mean \pm SD of the kinematic characteristics and the maximum bilateral isometric force for the leg extensor and flexor muscles in pre-, week 2, week 4, and post-tests of the progressive uphill-downhill group $(\mathrm{N}=7)$.

\section{MRS $\left(\mathrm{m} \cdot \mathrm{s}^{-1}\right) \quad$ SR $(\mathrm{Hz}) \quad$ SL $(\mathrm{m}) \quad$ CT $(\mathrm{ms}) \quad$ FT $(\mathrm{ms}) \quad$ MBIF_LEM $(\mathrm{N}) \quad$ MBIF_LFM $(\mathrm{N})$}

\begin{tabular}{c|ccccccc}
\hline Pre & $8.69 \pm 0.71^{\$}$ & $4.15 \pm 0.20$ & $2.10 \pm 0.22$ & $119 \pm 11^{\#}$ & $123 \pm 14$ & $2296.31 \pm 626.75^{\$}$ & $1420.48 \pm 302.28$ \\
Week 2 & $8.47 \pm 0.76^{\$}$ & $4.06 \pm 0.21$ & $2.09 \pm 0.15$ & $126 \pm 12$ & $118 \pm 13$ & $2268.84 \pm 336.20^{\$}$ & $1336.92 \pm 274.84$ \\
Week 4 & $8.56 \pm 0.74^{\$}$ & $3.94 \pm 0.16^{\$}$ & $2.18 \pm 0.23$ & $131 \pm 11$ & $123 \pm 14$ & $2559.08 \pm 580.68$ & $1328.33 \pm 347.02$ \\
Post & $9.09 \pm 0.68$ & $4.30 \pm 0.19$ & $2.13 \pm 0.17$ & $115 \pm 10^{\#}$ & $118 \pm 13$ & $2763.98 \pm 546.15$ & $1477.46 \pm 275.23$ \\
\end{tabular}

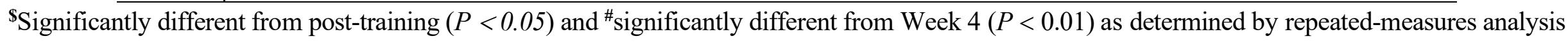
of variance and Tukey's HSD post-hoc tests. Abbreviations: $\mathrm{MRS}=$ maximum running speed, $\mathrm{SR}=$ step rate, $\mathrm{SL}=$ step length, $\mathrm{CT}=$ contact time, MBIF_LEM = maximal bilateral isometric force for the leg extensor muscles, MBIF_LFM = maximal bilateral isometric force for the leg flexor muscles. 
Table 3. Mean \pm SD of the kinematic characteristics and the maximum bilateral isometric force for the leg extensor and flexor muscles in pre-, post-training and after the detraining period of the training-detraining uphill-downhill group $(\mathrm{N}=7)$.

\begin{tabular}{c|ccccccc}
\multicolumn{2}{c}{ MRS $\left(\mathrm{m} \cdot \mathrm{s}^{-1}\right)$} & SR $(\mathrm{Hz})$ & SL $(\mathrm{m})$ & CT $(\mathrm{ms})$ & FT $(\mathrm{ms})$ & MBIF_LEM $(\mathrm{N})$ & MBIF_LFM $(\mathrm{N})$ \\
\hline Pre & $8.81 \pm 0.78$ & $4.27 \pm 0.21$ & $2.06 \pm 0.11$ & $123 \pm 14$ & $112 \pm 10$ & $2187.19 \pm 343.74$ & $1263.88 \pm 240.24$ \\
& & & & & & & \\
Post & $9.06 \pm 0.65^{*}$ & $4.38 \pm 0.17$ & $2.07 \pm 0.12$ & $120 \pm 8$ & $108 \pm 11$ & $2659.64 \pm 481.43^{*}$ & $1297.92 \pm 236.74$ \\
Dtrain & $8.94 \pm 0.66$ & $4.33 \pm 0.15$ & $2.07 \pm 0.10$ & $120 \pm 11$ & $111 \pm 11$ & $2455.92 \pm 251.09^{*}$ & $1356.86 \pm 218.35$ \\
& & & & & & &
\end{tabular}

*Significantly different from pre-training $(P<0.05)$ as determined by repeated-measures analysis of variance and Tukey’s HSD post-hoc tests.

Abbreviations: Dtrain $=$ after the detraining period, $\mathrm{MRS}=$ maximum running speed, $\mathrm{SR}=$ step rate, $\mathrm{SL}=$ step length, $\mathrm{CT}=$ contact time,

MBIF_LEM = maximal bilateral isometric force for the leg extensor muscles, MBIF_LFM = maximal bilateral isometric force for the leg flexor muscles. 
n-n......

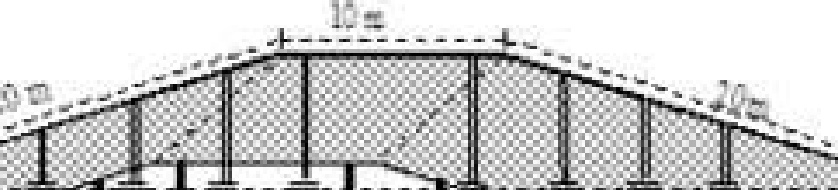
111 $11 \pi \mathrm{r}$ 
Figure 2
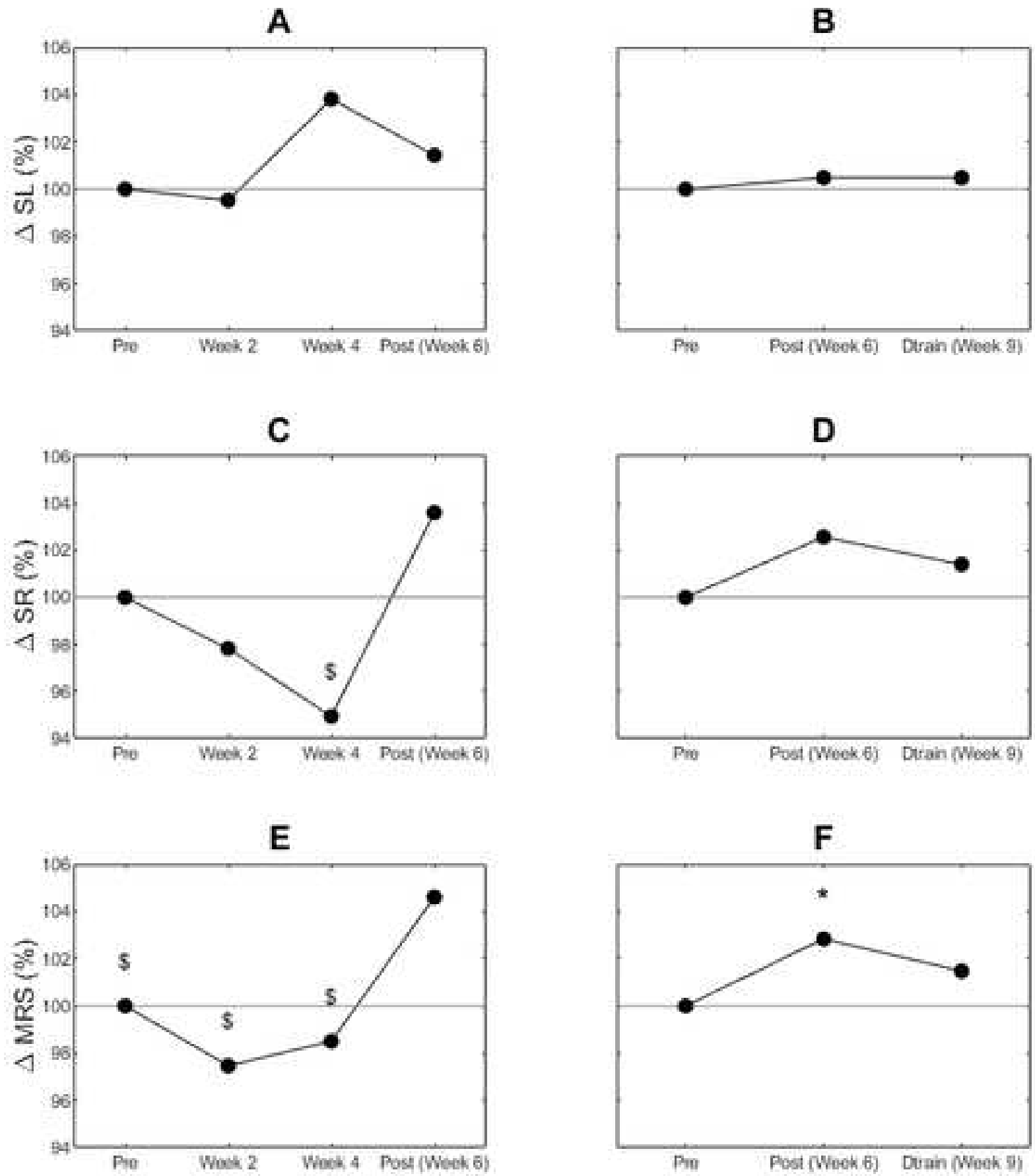
Knee extensors
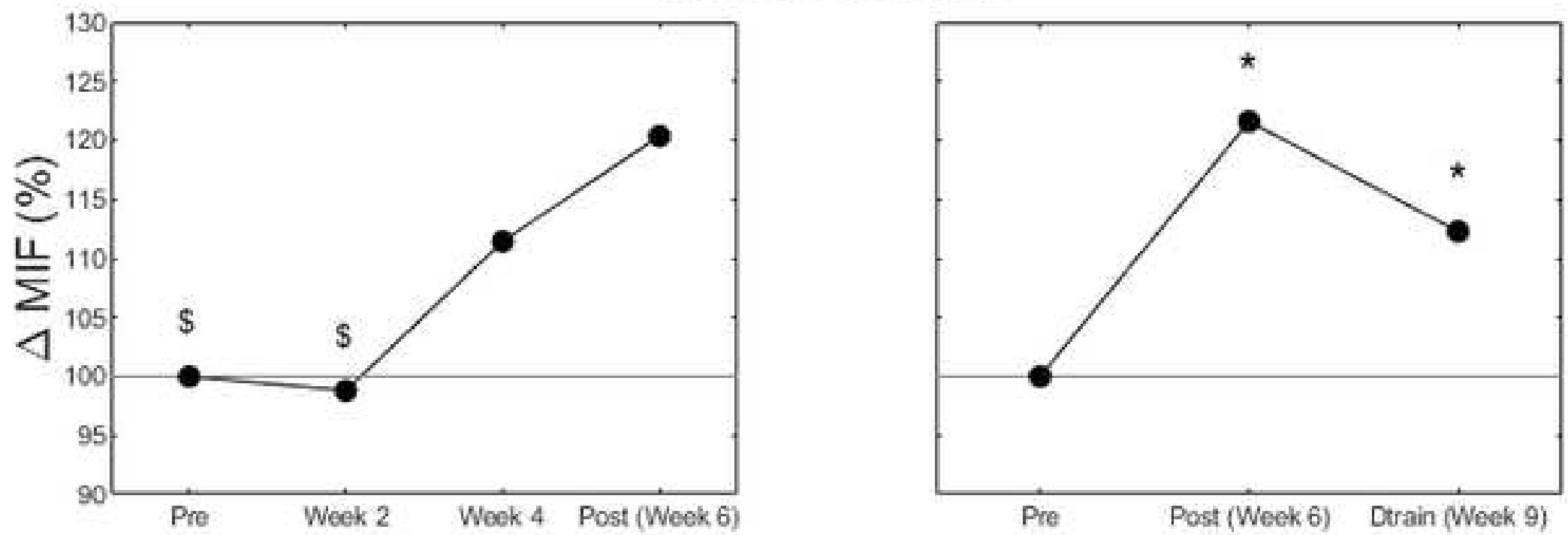

Knee flexors
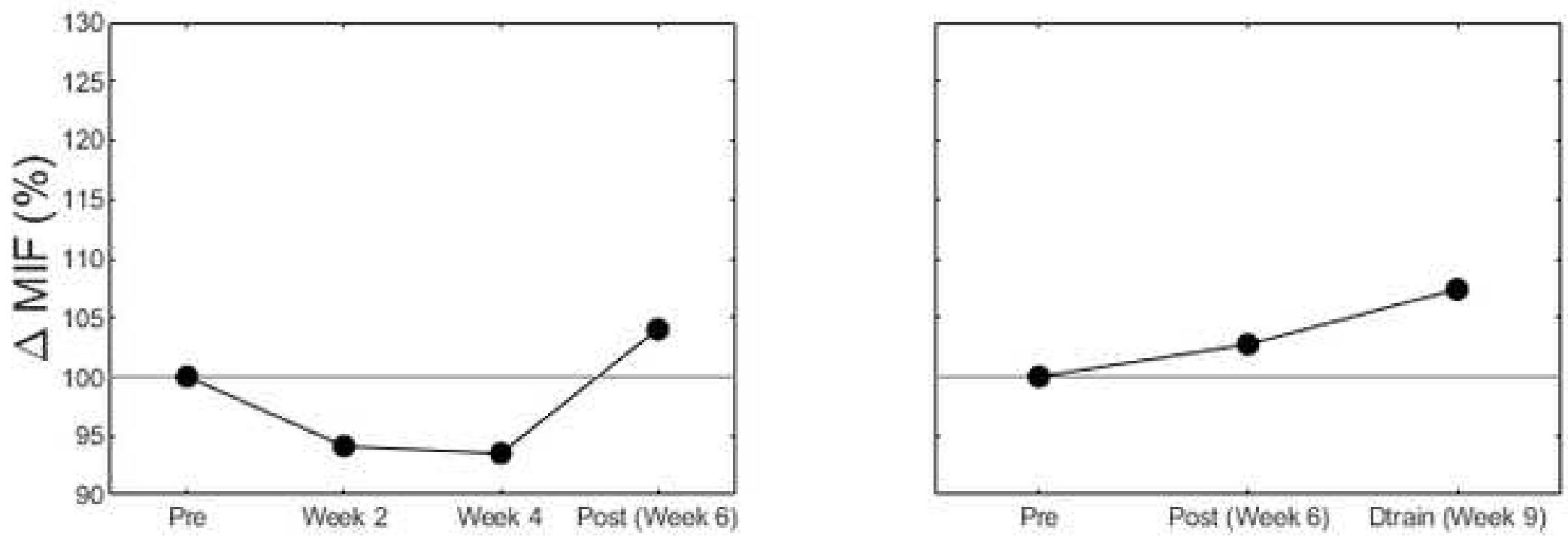